\title{
Atividades construtivistas diversificadas para introdução à Química: um estudo em uma escola da Amazônia ribeirinha'
}

Jesus Cardoso Brabo*, Vital Júnior de Oliveira Souza**

\section{Resumo}

Este artigo apresenta e discute a estrutura e a aplicação de um conjunto de atividades didáticas para o ensino de Química em uma turma de 25 estudantes do primeiro ano do ensino médio de uma escola pública localizada em uma comunidade ribeirinha do município de Breves, PA. Tratam-se de atividades inspiradas em diferentes estratégias, oriundas de sugestões didáticas de diversas pesquisas contemporâneas sobre o processo de ensino-aprendizagem de Química, que vão desde a realização de atividades de leitura analítica de textos informativos até a problematização de experimentos de Química relativamente simples para executar em salas de aula comuns. Foi possível observar um maior engajamento dos estudantes na realização das tarefas propostas bem como indícios qualitativos de melhor compreensão dos assuntos abordados ao longo das aulas.

Palavras-chaves: Diversificação de estratégias. Ensino de Química. Estratégias construtivistas.

Licenciado em Química pela Universidade Federal do Pará. Doutor em Ensino de Ciências pelo Programa Internacional de Doutorado em Ensino de Ciências (Universidade de Burgos, Espanha, e Universidade Federal do Rio Grande do Sul, Brasil). Pesquisador do Instituto de Educação Matemática e Científica da Universidade Federal do Pará. E-mail: brabo@ufpa.br

* Licenciado em Ciências Naturais e Mestre em Docência em Ciências e Matemática pela Universidade Federal do Pará. Professor pedagógico da Prefeitura Municipal de Breves e professor adjunto 4 de Química da Secretaria de Estado de Educação do Pará. E-mail: vitalvj@hotmail.com 


\section{Introdução}

Ter domínio da linguagem química e possuir habilidades básicas relacionadas a essa ciência nos ajuda a ler e interpretar o universo de coisas naturais e artificiais que nos cercam. Além disso, habilita-nos a argumentar cientificamente sobre fenômenos naturais ou processos tecnológicos que vivenciamos cotidianamente. Tais habilidades são essenciais para que possamos perceber e interferir em nossa própria qualidade de vida, como, por exemplo, o impacto ambiental provocado pelos rejeitos industriais e domésticos que poluem o ar, a água e o solo (ERLIKH, 2013; SANTOS, 2012). Ou seja, conhecimentos científicos, em geral, e químicos, em particular, além de nos ajudarem a lidar com questões da nossa própria vida, como cuidados com a saúde e compreensão do mundo que nos cerca, ainda nos possibilitam exercer nossa cidadania de forma mais prudente e sensata.

Embora conhecimentos de Química sejam essenciais para o cidadão contemporâneo, muito frequentemente ouvimos os jovens estudantes afirmarem que detestam Química. Pesquisas como as de Lythcott (1990), Cardoso e Colinvaux (2000) e Cracolice, Deming e Ehlert (2008) têm mostrado que tal rejeição é muito mais um produto do método de ensino geralmente empregado para ensinar Química no ensino médio do que do conteúdo da disciplina em si. Em outras palavras, a excessiva exigência de memorização de regras, fórmulas, conhecimentos factuais e termos cujos nomes não são familiares aos alunos acabam distorcendo a real utilidade e a beleza dos conhecimentos químicos.

Visando contornar esse e outros problemas que a adoção de métodos de ensino excessivamente expositivo-memorísticos implicam, vários educadores têm apresentado diferentes estratégias de ensino-aprendizagem alternativas, muitas das quais inspiradas em resultados de pesquisas sobre concepções alternativas e mudança conceitual (POSNER et al., 1982; THIELE; TREAGUST, 1991; MORTIMER, 1992; JUSTI; MENDONÇA, 2008).

Este artigo apresenta e discute a utilização de um conjunto de atividades didáticas práticas, para introduzir estudantes de ensino médio no estudo da Química. Tratam-se de atividades diversificadas, oriundas de sugestões didáticas de diferentes pesquisas contemporâneas sobre o processo de ensino-aprendizagem de Química, que vão desde a realização de atividades de leitura analítica de textos informativos até a problematização de experimentos relativamente simples, que podem ser 
realizados com reagentes alternativos, facilmente obtidos em supermercados ou farmácias, e vidrarias/aparatos que podem facilmente ser adquiridos em websites de compra e venda da internet.

As aulas-piloto foram desenvolvidas em uma comunidade ribeirinha do arquipélago do Marajó. Procurou-se descrever a realização das atividades indicando os eventuais impactos no comportamento dos estudantes, para que outros professores de Química possam avaliar a possiblidade de usar sistematicamente as atividades propostas em outras turmas/escolas de contextos análogos.

\section{Estratégias construtivistas para o ensino de Ciências/ Química}

Ao longo da década de 1970, pesquisas como a de Driver (1973) e a de Viennot (1976) deram início ao que ficou conhecido mais tarde como movimento das concepções alternativas. $\mathrm{Na}$ época, inspirados principalmente na psicologia piagetiana, pesquisadores educacionais da Europa e dos Estados Unidos da América dedicaram maior atenção à investigação dos conhecimentos prévios dos estudantes que influenciavam de maneira considerável a aprendizagem de conceitos científicos sobre determinados fenômenos da natureza.

O movimento das concepções alternativas gerou um significativo número de pesquisas a respeito de "ideias prévias" e/ou "conceitos intuitivos" dos estudantes sobre os mais diferentes assuntos científicos tratados em escolas e em universidades. É possível ter uma noção do que foi pesquisado sobre o assunto em catalogações como a de Pfundt e Duit (1994) e a de Özmen (2004). Ainda hoje é possível encontrar pesquisas sobre identificação e análise desse tipo de objeto.

Para saber o que os estudantes efetivamente pensavam sobre determinados assuntos, era necessário viabilizar formas de fazer com que eles externassem essas concepções de maneira direta (falando o que estavam pensando) ou indireta (deduzindo eventuais concepções alternativas a partir das respostas que os estudantes davam a determinados problemas experimentais e/ou lógicos). Com isso, foram criados diferentes protocolos de pesquisa para tentar "explicitar" e analisar, da melhor maneira possível, as diferentes concepções alternativas dos estudantes (TREAGUST, 1988). 
A abordagem inicial, mais centrada em aspectos do desenvolvimento cognitivo individual, inspirada em estudos piagetianos (PIAGET, 1929; INHELDER; PIAGET, 1969) ou na chamada Teoria da Aprendizagem Significativa (AUSUBEL; NOVAK; HANESIAN, 1978), gradativamente foi sendo contestada por estudos inspirados em ideias como as de Vygotsky (1978) e Bakhtin (1981), cujas teorias psicológicas consideravam de forma mais séria fatores relacionados às interações sociais. Embora tais abordagens tivessem alguns aspectos teóricos divergentes entre si, ambas acabaram sendo categorizadas sob o rótulo de "abordagem construtivista de ensino", uma vez que ambas criticavam a possibilidade de transmitir conhecimentos de forma direta, pregando a importância de os estudantes "construírem" seus conhecimentos interagindo com professores, colegas e materiais didáticos de forma ativa e interessada, e não apenas recebendo passivamente informações a serem memorizadas.

Desse conjunto de pesquisas surgiram diversas estratégias didáticas que visavam colocar o estudante como o centro das atenções, estimulando-o a apresentar e a testar seus conhecimentos prévios diante de problemas propostos em aula, dando-lhe oportunidade de questionar ideias, criar e testar hipóteses - planejando, coletando e analisando evidências -, entre outros comportamentos mais próximos do real pensar e do fazer científicos.

A partir de então, pesquisas sobre diferentes objetos e o processo de ensino-aprendizagem de ciências, não somente "concepções alternativas", tiveram um significativo crescimento em diferentes partes do mundo. Atualmente, alguns autores, como Cachapuz et al. (2001), afirmam que, já há algum tempo, a chamada Didática das Ciências (Science Education) é um campo específico de conhecimento relativamente consolidado.

Prediga, Observe e Explique (WHITE; GUNSTONE, 1992; BRABO; CAJUEIRO; VIEIRA, 2017), Ensino por Investigação (CARVALHO, 2013; WARTHA; LEMOS, 2016), atividades do tipo mão na massa (CHARPAK, 1996) e uso de mapas conceituais e diagramas V (NOVAK, 1990) são algumas estratégias didáticas derivadas de resultados e análises de pesquisas educacionais de cunho construtivista, que, de certa forma, já estão bastante disseminadas no âmbito acadêmico universitário da área de ensino de ciências, embora ainda sejam pouco utilizadas nas salas de aula de educação básica no Brasil. 
As leituras sobre o uso de diferentes estratégias construtivistas sobre ensino de noções básicas de Química inspiraram os autores deste artigo a propor um módulo de iniciação à química baseado nos princípios descritos a seguir.

- Sempre que possível, usar atividades do tipo mão na massa (hands-on): fazer os alunos manipularem aparatos de química, além de estimular a curiosidade, poderá dar-lhes a noção de como, de onde vêm e para que servem os objetos que eventualmente são ilustrados em livros didáticos, mas que os estudantes não têm noção de como realmente funcionam.

- Fazer os alunos produzirem e organizarem seus próprios dados: é uma prática típica do cotidiano científico que poderá ajudá-los a perceber de onde vêm e como esses dados são obtidos e organizados. Isso poderá ajudá-los a interpretar de forma mais adequada as tabelas e os gráficos nos textos didáticos de Química ou mesmo aqueles veiculados em noticiários impressos ou televisivos.

- Fazer os alunos tomarem consciência de suas eventuais concepções alternativas e contrastá-las com hipóteses cientificamente aceitas ao longo da história da ciência. Isso fará eles entenderem a natureza e a função das hipóteses científicas e suas relações com eventuais evidências usadas para confirmá-las ou refutá-las.

- Praticar leituras direcionadas de textos informativos: ensinando-lhes e dando-lhes oportunidades para a prática da marcação de trechos importantes, a elaboração de dúvidas, a produção de sínteses ou tópicos e a interconversão de texto em esquemas (mapas conceituais, organogramas, etc.).

- Incentivar a prática do diálogo aberto e respeitoso sobre ideias: fazendo perceber que, mesmo ideias equivocadas podem servir como base para aprendizado de conhecimentos científicos. Praticar o uso de diferentes tipos de argumentos, mostrando as diferenças e as aplicações de cada um deles (descrições, inferências, categorizações, etc.).

- Diversificar a natureza das atividades: potencializar o fator surpresa nas aulas, fazendo com que os estudantes fiquem curiosos sobre "o que o professor vai inventar hoje". Além disso, essa atitude evitará a monotonia do uso exclusivo ou exagerado de qualquer que seja a estratégia didática.

- Explorar prontamente as dúvidas que surgirem durante as aulas: apesar de exigir um grande preparo didático e domínio do conteúdo (científico, histó- 
rico e prático) por parte do professor, isso poderia trazer benefícios, seja em forma de esclarecimentos imediatos das dúvidas ou de encaminhamento de levantamentos bibliográficos sobre a questão, no caso de o professor não saber responder de pronto.

- Dar feedback sobre previsões, hipóteses e explicações apresentadas por meio de exposição e discussão de algumas das respostas em sala: os estudantes poderão tomar consciência de eventuais acertos e equívocos, e assim procurar não repetir eventuais erros de interpretação, raciocínio, ortografia, gramática, representação, etc. Para evitar possíveis constrangimentos, pode-se optar por comentar as respostas sem identificar quem as elaborou.

Tais princípios foram tomados como base para a elaboração de um conjunto de atividades sintetizadas nos Quadros 1 e 2.

Quadro 1 - Síntese da proposta de atividades de iniciação ao estudo de Química

\begin{tabular}{|c|c|c|c|}
\hline Aulas & Questão foco & Atividades com alunos & $\begin{array}{c}\text { Conhecimentos e habilidades } \\
\text { visados }\end{array}$ \\
\hline 1 & $\begin{array}{l}\text { Que cuidados básicos devem } \\
\text { ser tomados ao manipular e } \\
\text { observar experimentos de } \\
\text { Química? Quais as principais } \\
\text { vidrarias e aparatos comumen- } \\
\text { te utilizadas por químicos? }\end{array}$ & $\begin{array}{l}\text { Ler e discutir a respeito de questões } \\
\text { relacionadas a cuidados na manipu- } \\
\text { lação de experimentos, elaborar um } \\
\text { guia de segurança e um glossário de } \\
\text { aparatos de Química. }\end{array}$ & $\begin{array}{l}\text { Ler e compreender textos } \\
\text { sobre procedimentos de se- } \\
\text { gurança. } \\
\text { Elaborar glossário e normas } \\
\text { de segurança de acordo com } \\
\text { os itens disponíveis no kit do } \\
\text { professor. }\end{array}$ \\
\hline II & $\begin{array}{l}\text { Pra que servem certas vidra- } \\
\text { rias e aparatos químicos? }\end{array}$ & $\begin{array}{l}\text { Realizar procedimentos que visem } \\
\text { ao reconhecimento de instrumentos } \\
\text { científicos (vidrarias e aparatos) e de } \\
\text { suas respectivas utilidades. }\end{array}$ & $\begin{array}{l}\text { Manusear vidrarias e apara- } \\
\text { tos químicos, realizando me- } \\
\text { didas simples e comparando } \\
\text { a precisão de medidas entre } \\
\text { diferentes vidrarias apresen- } \\
\text { tadas. }\end{array}$ \\
\hline III & $\begin{array}{l}\text { Como funciona um termôme- } \\
\text { tro? }\end{array}$ & $\begin{array}{l}\text { Ler e discutir as utilidades e os peri- } \\
\text { gos do uso de mercúrio. } \\
\text { Fazer medidas de temperatura, or- } \\
\text { ganizando-as em tabelas e gráficos. }\end{array}$ & $\begin{array}{l}\text { História de elementos quími- } \\
\text { cos, poluição por mercúrio, } \\
\text { leitura e produção de tabelas } \\
\text { e gráficos. }\end{array}$ \\
\hline IV & $\begin{array}{l}\text { É possível coletar e medir ga- } \\
\text { ses produzidos em uma rea- } \\
\text { ção química? }\end{array}$ & $\begin{array}{l}\text { Ler e discutir aspectos relacionados } \\
\text { a reações químicas com produção } \\
\text { de gases. } \\
\text { Observar, predizer e explicar fenô- } \\
\text { menos químicos. }\end{array}$ & $\begin{array}{l}\text { História da química, produ- } \\
\text { ção e testagem de hipóte- } \\
\text { ses, manipulação de apara- } \\
\text { tos químicos. }\end{array}$ \\
\hline
\end{tabular}

Fonte: elaboração dos autores. 
Quadro 2 - Síntese da proposta de atividades sobre propriedades da matéria

\begin{tabular}{|c|c|c|c|}
\hline Aulas & Questão foco & Atividades com alunos & Conhecimentos e habilidades visados \\
\hline $\mathrm{lb}$ & $\begin{array}{l}\text { O que são proprie- } \\
\text { dades da matéria? }\end{array}$ & $\begin{array}{l}\text { Discussão introdutória do assunto e } \\
\text { produção de um mapa conceitual a } \\
\text { partir da leitura de texto. }\end{array}$ & $\begin{array}{l}\text { Caracterização e classificação das pro- } \\
\text { priedades da matéria. } \\
\text { Sintetização de ideias em forma de es- } \\
\text { quemas gráficos. }\end{array}$ \\
\hline Ilb & $\begin{array}{l}\text { Por que objetos flu- } \\
\text { tuam ou afundam em } \\
\text { água? }\end{array}$ & $\begin{array}{l}\text { Determinação experimental de va- } \\
\text { lores de densidade de diferentes } \\
\text { objetos e substâncias. } \\
\text { Tabulação e análise de dados obti- } \\
\text { dos em medições. }\end{array}$ & $\begin{array}{l}\text { Determinação de volumes de objetos } \\
\text { com diferentes formatos. } \\
\text { Compreensão de conceitos de densi- } \\
\text { dade de sólidos e líquidos. } \\
\text { Formulação e testagem de hipóteses. }\end{array}$ \\
\hline IIIb & $\begin{array}{l}\text { Como funcionam os } \\
\text { submarinos? }\end{array}$ & \multirow{3}{*}{$\begin{array}{l}\text { Testagem de hipóteses, utilizando } \\
\text { aparatos científicos para buscar } \\
\text { evidências a favor das hipóteses } \\
\text { propostas ou contra elas. }\end{array}$} & $\begin{array}{l}\text { Compreensão de conceitos de pressão } \\
\text { atmosférica, variação de pressão em } \\
\text { líquidos e empuxo. }\end{array}$ \\
\hline $\mathrm{IVb}$ & $\begin{array}{l}\text { Por que o gelo flutua } \\
\text { em água? }\end{array}$ & & $\begin{array}{l}\text { Compreensão do processo de variação } \\
\text { de densidade em função da tempera- } \\
\text { tura. }\end{array}$ \\
\hline $\mathrm{Vb}$ & Gás tem peso? & & $\begin{array}{l}\text { Compreensão de conceitos de densi- } \\
\text { dade de gases. }\end{array}$ \\
\hline VIb & $\begin{array}{l}\text { que acontece ao } \\
\text { longo do aquecimen- } \\
\text { to de certas substân- } \\
\text { cias e misturas? }\end{array}$ & $\begin{array}{l}\text { Interpretação e explicação de com- } \\
\text { portamentos de substâncias e mis- } \\
\text { turas durante aquecimento gradual, } \\
\text { expressos em gráficos de linhas. }\end{array}$ & $\begin{array}{l}\text { Pontos de fusão e ebulição. } \\
\text { Interpretação de gráficos de linha. }\end{array}$ \\
\hline VIIb & $\begin{array}{l}\text { Qual a quantidade de } \\
\text { sal que posso dissol- } \\
\text { ver em água? }\end{array}$ & $\begin{array}{l}\text { Determinação experimental de va- } \\
\text { lores de solubilidade de algumas } \\
\text { substâncias cotidianas. } \\
\text { Tabulação e análise de dados obti- } \\
\text { dos em medições. }\end{array}$ & $\begin{array}{l}\text { Solubilidade. } \\
\text { Análise de gráficos de solubilidade em } \\
\text { função da temperatura. }\end{array}$ \\
\hline VIIIb & $\begin{array}{l}\text { O que aprendemos } \\
\text { sobre propriedades } \\
\text { da matéria? }\end{array}$ & $\begin{array}{l}\text { Reflexão sobre a aprendizagem du- } \\
\text { rante as aulas e esclarecimentos de } \\
\text { eventuais dúvidas pendentes. }\end{array}$ & $\begin{array}{l}\text { Revisão e consolidação de conceitos } \\
\text { estudados. } \\
\text { Sintetização de ideias em forma de tó- } \\
\text { picos ou infográficos. }\end{array}$ \\
\hline
\end{tabular}

Fonte: elaboração dos autores.

O conjunto de atividades proposto no Quadro 1 tem por objetivo fazer com que os estudantes possam ter um contato inicial estimulante com “coisas” de Química. Manusear in loco e tomar conhecimento das utilidades específicas de algumas vidrarias e equipamentos científicos podem ser atividades bastante estimulantes para alunos, haja vista se tratarem de coisas que eventualmente possam ter sido vistas por eles em filmes ou em livros de ciências e que, provavelmente, habitam o imaginário de muitos estudantes. Naturalmente, tal conjunto de atividades deverá 
ser planejado de acordo com os materiais disponíveis na escola ou no kit particular do professor. Todavia, é importante que os estudantes possam examinar de perto e utilizar o máximo de vidrarias e equipamentos disponíveis, para que possam fazer perguntas e ir se habituando aos nomes e às utilidades de cada objeto, além de tomar conhecimento dos eventuais cuidados de segurança exigidos para cada aparato ou vidraria.

Além de apresentar os aparatos científicos disponíveis, o professor poderá envolver os alunos em problemas de determinação de massa, volume, temperatura de sólidos, líquidos e gases. Eles podem comparar, por exemplo, a precisão de medidas obtidas por meio do uso de diferentes vidrarias (proveta e bureta, por exemplo) e montar aparatos de coleta de gases produzidos, por exemplo, na mistura de compridos efervescentes em água. Outra possiblidade é a exploração de narrativas históricas relacionadas às propriedades dos materiais. O professor pode apresentar descobertas científicas e/ou práticas e processos pré-científicos (como as práticas de Alquimia) de onde se originaram os problemas e/ou técnicas que possibilitaram o desenvolvimento da Química, como também pode pedir que os alunos pesquisem sobre isso na internet, para discutir, durante as aulas, as informações eventualmente trazidas por eles.

Nesse módulo, também podem ser explorados textos e/ou vídeos sobre segurança na manipulação de aparatos científicos, tirando eventuais dúvidas dos alunos sobre as informações apresentadas, bem como sugerindo a elaboração de glossários ou infográficos a partir dessas fontes de informação. Os materiais mais bem elaborados podem ser fixados nas paredes da sala de aula, servindo para consultas rápidas e ajudando os estudantes a memorizarem termos e procedimentos importantes.

O conjunto de atividades esquematizado no Quadro 2 foi pensado para que os estudantes tenham oportunidade de estudar textos escritos sobre propriedades da matéria e em seguida manipular experimentos, criar e testar suas hipóteses, produzir gráficos sobre variação de temperatura no decorrer de determinados processos de mudanças de estado, medir e comparar determinadas propriedades de diferentes substâncias químicas.

Há muitas possibilidades de explorar fenômenos relacionados às propriedades da matéria. $\mathrm{O}$ conceito de densidade, por exemplo, além da determinação direta ou indireta (com balança e aparatos para determinação de volume dos materiais), pode ser discutido com o uso de experimentos como o submarino na garrafa PET 
(TENÓRIO, 2011) e o aquário de bolhas flutuantes (TENÓRIO, 2012). A determinação na prática de pontos de fusão, ebulição e solubilidade de diferentes materiais tem grande potencial para fazer os alunos compreenderem a significado científico desses termos.

Nas atividades sugeridas nesse módulo, também é possível explorar a propriedades químicas de materiais do cotidiano dos estudantes. Estudantes de áreas urbanas podem sugerir a determinação de propriedades de materiais vendidos em farmácias, supermercados, lojas de materiais de construção, etc. Enquanto estudantes de áreas rurais podem explorar propriedades de materiais encontrados na natureza, usados como remédios naturais ou em atividades de agricultura, pesca ou outras práticas humanas peculiares ao respectivo contexto cultural.

Por fim, mas não menos importante, os professores poderão também envolver os estudantes na elaboração de sínteses (mapas conceituais, infográficos, reportagens, resumos, etc.) do que aprenderam durante as atividades, para compartilhar com os colegas e a comunidade escolar seus aprendizados e suas produções textuais e/ ou audiovisuais.

\section{Aplicação-piloto das atividades propostas}

Para avaliar a viabilidade de utilização e o impacto que as atividades propostas no comportamento e na aprendizagem dos estudantes, foi realizada uma intervenção didática em uma turma de ensino médio do Sistema Modular de Ensino (Some) ${ }^{2} \mathrm{em}$ uma escola da rede pública estadual, localizada em uma comunidade ribeirinha do interior do estado do Pará.

No Some da Secretaria de Estado da Educação do Pará (Seduc/PA), as aulas são organizadas em módulos, nos quais cada disciplina é ministrada em determinados períodos de aulas intensivas (manhã e tarde). No caso, cada módulo da disciplina de Química possui carga horária de 80 horas para ser apresentado durante 15 dias seguidos. Ao longo do ano, durante cada 15 dias, dois professores, cada um com uma disciplina diferente, revezam-se ministrando aulas para uma turma (um pela manhã e outro à tarde). Durante esse período, os professores apresentam um "módulo" da disciplina, cujo conteúdo é definido pela Seduc/PA. O Some foi criado, em caráter emergencial, em 1982, para tentar contornar a falta de professores e infraestrutura escolar em pequenas comunidades rurais distantes das sedes dos 
municípios ou de difícil acesso. Embora tenha sido criado como uma ação emergencial, até o momento continua ativo em praticamente todo o território paraense (RODRIGUES; SILVA, 2018).

Com cuidado de não prejudicar o conteúdo programático pré-estabelecido pela Seduc/PA e, ao mesmo tempo, procurando inserir elementos inovadores nas aulas que já estavam programadas para acontecer durante o ano de 2018, as atividades propostas foram colocadas em prática em uma escola de uma comunidade ribeirinha do município de Breves, PA, na qual um dos autores deste artigo atua, há mais de três anos, como professor de Química. Participou da atividade uma turma da modalidade Some, composta por 25 estudantes do primeiro ano do ensino médio, com idades entre 16 e 25 anos.

A coleta e a análise dos dados foram realizadas com base na abordagem qualitativa de pesquisa, considerando a compreensão dos processos de ensino e aprendizagem em um contexto educacional peculiar. Especificamente, foram utilizadas técnicas oriundas da etnografia (ANDRÉ, 1995), para coletar dados - em forma de anotações em diários de campo, gravações em áudio de entrevistas e/ou episódios de realização de tarefas propostas, além das produções escritas e desenhos dos estudantes (em folha de papel e na lousa) - que pudessem servir como objetos de análise para averiguar eventuais aprendizagens, mudanças de opinião e insights que, ocasionalmente, os estudantes apresentassem durante a realização das aulas.

Para minimizar os riscos de perder dados importantes, cada estudante foi orientado a produzir uma espécie de portfólio em seu caderno, uma vez que a maioria das atividades envolvia registros escritos (tópicos, hipóteses, explicações, tabelas, gráficos, esquemas, desenhos, etc.). Foi informado a eles que o registro das atividades no caderno serviria para compor o conceito a ser atribuído a cada um, ao final das atividades do módulo.

Os dados brutos foram submetidos à análise de conteúdo (BARDIN, 2009), para que, dessa forma, fosse possível selecionar episódios de aprendizagem que pudessem servir de evidências para corroborar eventuais conclusões relacionadas às atividades de ensino propostas ou a elementos que oferecessem pistas para eventuais mudanças que se façam necessárias em determinadas atividades e/ou na organização do módulo como um todo.

A fim de preservar a identidade dos estudantes, ao mencionar transcrições de perguntas, afirmações ou textos produzidos ao longo das aulas, utilizam-se 
pseudônimos que consistem em um nome fictício seguido pela idade do respectivo aluno. Para efeito de preservação da privacidade e cumprimento de normas éticas, todos os estudantes citados no trabalho assinaram termos de consentimento livre e esclarecido.

\section{Resultados e discussão}

Para expor os resultados da realização das atividades, optou-se por relatá-las na ordem cronológica de realização, descrevendo comportamentos e ilustrando os insights dos estudantes (perguntas, conclusões, inquietações, etc.) ao longo de cada atividade proposta, comentando possíveis evidências qualitativas do impacto das referidas tarefas no comportamento e na aprendizagem dos estudantes.

Durante a primeira aula foi visível a empolgação dos estudantes ao saber que iriam conhecer e manipular aparatos e vidrarias químicos colocados sobre a mesa do professor. Embora, inicialmente, a maioria dos alunos tenha se mostrado tímida, não demorou muito para alguns começarem a fazer perguntas e comentários sobre o que estava sendo apresentado. Como não havia disponibilidade de aparatos e vidrarias para todos os estudantes, antes de cada tarefa proposta, um aluno era sorteado para realizar a tarefa e, sob supervisão do professor, manipulava as respectivas vidrarias. Durante essas atividades, muitas questões e comentários foram surgindo, tais como:

Quer dizer que quanto mais "fina" for a parte do "vidro" que a gente mede, mas precisa será a medida (Lara_18)?

Hum... Daqui que vem... "bebê de proveta" (Ana_16)?

Mas pra quê é necessário tanta precisão nas medidas (Alan_19)?

Por que a maioria dessas "coisas" é de vidro? Se fossem de plásticos seriam mais baratos e resistentes, não é (Davi_18)?

Não tem uma substância menos tóxica do que o mercúrio pra "fazer" termômetros (Isa_17)?

Na segunda aula, dando continuação à manipulação dos aparatos e vidrarias, os estudantes foram desafiados a criar um método para coletar e medir o volume de gases (formados a partir da reação de um comprimido efervescente e água) com 
os aparatos e as vidrarias disponíveis. Ao contrário do que o professor imaginou, um dos alunos rapidamente deu a seguinte ideia:

[...] podemos usar um tubo plástico conectado a esse frasco [erlenmeyer] para desviar o gás produzido pelo Sonrizal para o interior de um vidro desse tipo [proveta] invertido, cheio d'água, com a boca imersa em tigela de vidro, também cheia de água (Hugo_19).

Ao ser indagado sobre como conseguiu pensar tão rápido, justificou: "Tive essa ideia, por que quando era criança costumava fazer isso. Soprando em canudinhos e copos transparentes virados em bacias de água" (Hugo_19). Com isso, os estudantes puderam ficar um tempo considerável medindo qual a quantidade máxima de gás produzida por certos pedaços de comprimidos efervescentes e, assim, tentar estimar a quantidade total de gás produzida por um comprimido inteiro. Discutindo como fazer isso, conseguiram chegar à conclusão de que era necessário utilizar a balança para ajudar a fazer essa estimativa, pesando os comprimidos inteiros e os pedaços usados na reação. Já que, quando tentaram medir a quantidade de gás produzida por um comprimido inteiro, o gás "transbordava” da proveta.

$\mathrm{Na}$ aula seguinte, sobre propriedades da matéria, os estudantes inicialmente foram orientados a ler um pequeno texto de duas páginas sobre o assunto, marcar trechos que considerassem importantes e formular perguntas que surgissem com a leitura do texto.

Após apresentarem e comentarem os trechos que julgaram importantes, os alunos receberam a tarefa de determinar a densidade de diferentes objetos (pedaços de isopor, parafusos, porcas, moedas, papel alumínio, uva, caroço de açaí, caroço de pupunha, ovo de galinha, pequeno cilindro de plástico com mercúrio líquido), utilizando os materiais disponíveis sobre a mesa (balança, régua, paquímetros, vidrarias, água, etc.). A densidade de cada objeto era determinada e colocada no quadro. Os estudantes tiveram dificuldades em determinar a densidade de objetos de volume irregular (parafusos, porcas, etc.), por isso, o professor explicou como poderia estimar o volume do objeto pela medida da quantidade de líquido deslocada pela imersão do objeto em uma proveta com água.

Com os respectivos valores de densidade de cada objeto escritos no quadro, foi fácil os alunos preverem quais deles afundariam e quais flutuariam em água "pura" e na mistura saturada de água e sal. Mesmo assim, ficaram surpresos ao observar que objetos de metal "boiavam" em mercúrio líquido! 
Agora sei por que a minha vó costumava colocar os ovos na água pra ver se não estavam podres (Dora_16)!

Nunca imaginei que uma porca de aço pudesse "flutuar" em alguma coisa (Eva_17)!

E o que afunda em mercúrio (Isa_17)?

Por que ele [o mercúrio] "é mole" e os outros metais são "duros" (Eric_19)?

Aproveitando a curiosidade sobre o mercúrio, na aula seguinte, o professor exibiu um vídeo sobre a história da Alquimia e discutiu vários aspectos mostrados no vídeo, buscando enfatizar a importância de utilizar as propriedades dos materiais para diferenciá-los entre si e aproveitá-los para diferentes finalidades tecnológicas.

$\mathrm{Na}$ aula seguinte, foi mostrado aos alunos um brinquedo conhecido como "submarino na garrafa” (TENÓRIO, 2011), dando-lhes a tarefa de descobrir qual o segredo do submarino de tampa de caneta para emergir e submergir ao apertar a lateral da garrafa. Após muitas discussões, uma das equipes escreveu o seguinte como resposta:

O submarino sob e desce por que quando apertamos a lateral da garrafa entra mais água no buraco da tampinha da caneta e assim ela fica mais pesada... densa, com isso ela desce. Parando de apertar a garrafa o ar que está dentro da tampinha expulsa a água e diminui a densidade dela, fazendo ela subir (Jean_22).

As outras equipes disseram que fizeram o mesmo raciocínio, mas não sabiam explicar "em palavras" escritas, só falando.

$\mathrm{Na}$ aula seguinte, foi realizado um dos experimentos que mais chamaram atenção dos alunos: o aquário de bolhas flutuantes (TENÓRIO, 2012). O professor utilizou a estratégia "Prediga, Observe e Explique" (WHITE; GUNSTONE, 1992), explicando aos estudantes, inicialmente, que a mistura de $500 \mathrm{~g}$ de bicabornato de sódio e $500 \mathrm{~mL}$ de vinagre no aquário de vidro formaria bastante gás carbônico $\left(\mathrm{CO}_{2}\right)$ e pedindo para que fizessem previsões sobre o que aconteceria se bolhas de sabão fossem jogadas no interior desse aquário de $\mathrm{CO}_{2}$ (afundariam, flutuariam ou seriam expelidas?) e o "porquê" da respectiva previsão.

As bolhas vão afundar, pois o ar que tem dentro do aquário é o mesmo que tem fora (Jean_22).

Vão ser expulsas, pois a reação está produzindo um "vento" que vai empurrar as bolhas (Elis_17).

Acho que vão flutuar, mas não sei explicar por quê (Jade_24). 
O professor jogou bolhas de sabão de diversos tamanhos e explicou aos estudantes que o gás carbônico é um gás mais denso que o ar, por isso, o conjunto bolha + ar, dependendo do tamanho, flutua no gás carbônico, mesmo que não seja possível observá-lo a olho nu, ele está lá. Aproveitou para perguntar por que algumas bolhas (as menores) acabavam flutuando em um nível um pouco abaixo do nível das bolhas maiores? Sabendo que a flutuação tinha relação com a densidade, alguns alunos prontamente responderam.

Ah, deve ser a mesma coisa do submarino, a bolhas menores são mais densas que a maiores e por isso vão mais pro fundo (Hugo_19).

Isso mesmo! A densidade da película de sabão + ar varia com o tamanho da bolha. Se fosse só a película de sabão (sem o ar) nem flutuaria... nem um pouquinho (Rita_17).

Quanto mais ar dentro da bolha menos densa ela fica (Luna_18)!

$\mathrm{Na}$ aula seguinte, o professor montou aparatos para que os estudantes pudessem medir a variação da temperatura ao longo do aquecimento de duas amostras: uma de $200 \mathrm{~mL}$ de água destilada contendo gelo e outra de $200 \mathrm{~mL}$ de uma mistura de água, sal e gelo. Duas equipes de estudantes foram instruídas a coletar e medir a temperatura a cada 10 segundos, colocando os valores em uma tabela de "tempo x temperatura" escrita no quadro. Depois da coleta dos dados, o professor ensinou a traçar os respectivos gráficos de tempo versus temperatura das amostras e mostrou aos alunos que somente a água destilada apresentava padrão de variação de temperatura com patamares regulares. Em seguida, utilizou slides para explicar gráficos de variação de temperatura e de outras substâncias puras e significado de pontos de fusão e ebulição, chamando atenção dos estudantes para o fato de que, assim como a densidade, os pontos de fusão e ebulição eram outras importantes propriedades de substâncias puras.

Os alunos não demonstraram muita empolgação durante essa aula, talvez pelo fato de que nas anteriores tenham se surpreendido com os fenômenos apresentados e participado mais ativamente dos experimentos propostos.

Esse negócio de fazer gráfico é muito chato! Tem que ter paciência e prestar muita atenção no termômetro e no relógio (Alex_19)!

Hoje o senhor explicou muito e a gente ficou só observando (Ana_16). 
A aula seguinte tratou sobre solubilidade. Após o professor ter anunciado e explicado, por meio de slides, os conceitos de solubilidade, solvente, soluto, etc., foi solicitado aos estudantes que, com ajuda de balança, béqueres e colheres descartáveis, determinassem as quantidades máximas de sal e açúcar que poderiam ser complementarmente dissolvidas em $100 \mathrm{~mL}$ de água e também em $100 \mathrm{~mL}$ de álcool etílico hidratado, escrevendo em uma tabela no quadro os valores obtidos por cada equipe (sal em água, açúcar em água, sal em álcool, açúcar em álcool).

Após os estudantes inserirem todos os valores obtidos, o professor completou as tabelas com valores de solubilidade padrão (obtidos em uma fonte confiável) e comparou com os resultados obtidos pelos estudantes, comentando possíveis fontes de erros (diferença da temperatura nas amostras em relação às amostras de solubilidade padronizadas, dificuldade de perceber o ponto de saturação exato, etc.).

Com ajuda de um gráfico de solubilidade em função da temperatura de algumas substâncias, o professor mostrou e comentou eventuais peculiaridades dessa variação. Por exemplo, em qual faixa de temperatura certas substâncias são mais solúveis que outras, que a solubilidade de algumas substâncias diminui com a temperatura, entre outras questões.

Para efeito de revisão e síntese dos conhecimentos apresentados ao longo dos módulos, os estudantes receberam instruções e exemplos de como fazer mapas conceituais e infográficos e, depois, foram divididos em equipes. Cada equipe ficou responsável por compor um infográfico ou um mapa conceitual sobre um dos seguintes temas: cuidados na manipulação de vidrarias e aparatos químicos; medições de volume, massa e temperatura; propriedades da matéria (resumo); densidade; pontos de fusão e ebulição; solubilidade de substâncias em água. Para isso, além do que tinham aprendido em sala de aula, foram orientados a consultar os livros didáticos de Química disponíveis na escola.

Para encerar o módulo, cada equipe apresentou seu infográfico ou mapa conceitual para a turma, que, por sua vez, foi orientada a apontar possíveis melhorias ou eventuais correções necessárias em cada esquema apresentado. Para contornar o problema de alguns alunos evitarem comentar o trabalho dos colegas por receio de sofrer retaliações por "criticar o trabalho dos outros", o professor orientou os alunos que estavam expondo seus trabalhos a não se preocuparem caso não soubessem responder uma ou outra pergunta sobre o trabalho e que ele poderia esclarecer 
se fosse necessário. Assim, os alunos ficaram mais tranquilos em interagir e tirar dúvidas sobre os trabalhos apresentados pelas diferentes equipes.

\section{Considerações finais}

Durante a realização das atividades, foi possível notar grande engajamento e interesse por parte dos estudantes em realizar as tarefas propostas, colocar em pauta suas opiniões e levantar questões sobre os assuntos trabalhados. Embora isso tenha acontecido paulatinamente, à medida que alguns alunos tomavam iniciativa de indagar, outros seguiam o exemplo. Com isso, as aulas se tornaram bastante participativas e alguns alunos lamentaram quando o período do módulo acabou.

Apesar de as atividades não se aprofundarem em definições, regras e classificações e exigirem muito mais tempo do que aulas expositivas convencionais para tratar de conceitos que muitos professores considerariam como relativamente triviais (tais como densidade), é possível notar, por meio do comportamento, das indagações e dos insights apresentados pelos estudantes da turma investigada, que as atividades os estimularam a buscar compreender de fato os problemas propostos, permitindo-lhes um aprendizado mais significativo, embora básico. Alguns alunos acharam "estranho" o professor "explicar pouco no quadro", mas gostaram de "fazer as experiências" e expressar suas dúvidas.

Os resultados da aplicação do conjunto de atividades proposto, embora preliminares, apresentaram evidências qualitativas do potencial de motivação para o aprendizado de conceitos e habilidades básicas tratados ao longo das aulas. Todavia, naturalmente, é necessário fazer mais pesquisas para avaliar os efeitos de aplicação deste e de outros módulos análogos em diferentes turmas e contextos educativos, para poder afirmar com maior segurança que o modelo didático apresentado é, de fato, mais apropriado do que outros métodos para o ensino de conceitos e habilidades básicas de Química.

Esperamos que os princípios do uso combinado de estratégias diversificadas, com atividades hands-on e de produção de esquemas de estimulação metacognitivas (mapas conceituais, infográficos etc.), para organizar e sintetizar aprendizagens, tratados neste artigo, possam ser objeto de novas pesquisas e sirvam de base para a composição de outros módulos de atividades para o ensino de ciências ou, ainda, 
como objeto de conhecimentos e/ou habilidades que devem ser aprendidos pelos estudantes ao longo da educação básica.

\section{Diversified constructivist activities for introduction to Chemistry: a study in a riparian Amazonian school}

\section{Abstract}

This article presents and discusses the structure and application of a set of didactic activities for the teaching of Chemistry in a group of twenty five students of the first year of High School, from a public school located in a community on the riverside of the municipality of Breves, Pará, Brazil. These are activities inspired by different strategies, resulting from didactic suggestions of several contemporary researches on the teaching-learning process of Chemistry, ranging from the activities of analytical reading of informative texts to the problematization of relatively simple chemistry experiments perform in ordinary classrooms. It was possible to observe a greater engagement of the students in the accomplishment of the proposed tasks as well as qualitative evidences of a better understanding of the subjects addressed throughout the classes.

Keywords: Diversification of strategies. Chemistry teaching. Constructivist strategies.

\section{Notas}

1 O presente trabalho foi realizado com apoio da Coordenação de Aperfeiçoamento de Pessoal de Nível Superior (Capes), Brasil.

2 O Some foi regulamentado pela Lei no 7.806, de 29 de abril de 2014, embora esteja há mais de 30 anos em funcionamento em diversas escolas públicas de comunidades rurais paraenses (RODRIGUES; SILVA, 2018).

\section{Referências}

ANDRÉ, M. E. D. A. Etnografia da prática escolar. Campinas: Papirus, 1995.

AUSUBEL, D.; NOVAK, J. D.; HANESIAN, H. Educational psychology, a cognitive view. New York: Holt, Reinhart and Winston, 1978.

BAKHTIN, M. M. The dialogic imagination: four essays. Austin: University of Texas Press, 1981.

BARDIN, L. Análise de conteúdo. Lisboa: Edições 70/LDA, 2009.

BRABO, J. C.; CAJUEIRO, D. D. S.; VIEIRA, B. N. Alfabetização científica e linguística com Cloze e P.O.E.: tratamento de água em comunidades ribeirinhas. Experiências em Ensino de Ciências, Cuiabá, v. 12, n. 4, p. 18-29, 2017. Disponível em: http://www.if.ufmt.br/eenci/artigos/ Artigo_ID364/v12_n4_a2017.pdf. Acesso em: 02 abr. 2019. 
CACHAPUZ, A. et al. A emergência da didáctica das ciências como campo específico de conhecimento. Revista Portuguesa de Educação, Braga, v. 14, n. 1, p. 155-195, 2001.

CARDOSO, S. P.; COLINVAUX, D. Explorando a motivação para estudar Química. Química Nova, São Paulo, v. 23, n. 3, p. 401-404, 2000. Disponível em: https://doi.org/10.1590/s010040422000000300018. Acesso em: 02 abr. 2019.

CARVALHO, A. M. P. (org.). Ensino de ciências por investigação: condições para implementação em sala de aula. São Paulo: Cengage Learning, 2013.

CHARPAK, G. La Main à la pâte: Les sciences à l'école primaire. Paris: Flammarion, 1996.

CRACOLICE, M. S.; DEMING, J. C.; EHLERT, B. Concept learning versus problem solving: a cognitive difference. Journal of Chemical Education, Washington, v. 85, n. 6, p. 873, 2008. Disponível em: https://doi.org/10.1021/ed085p873. Acesso em: 02 abr. 2019.

DRIVER, R. The representations of conceptual frameworks in young adolescents science students. Tesis Doctoral. Urbana-Illinois: University of Illinois, 1973.

ERLIKH, G. V. What chemistry should be taught in modern schools? Russian Journal of General Chemistry, St. Petersburg, v. 83, n. 4, p. 794-805, 2013. Disponível em: https://doi.org/10.1134/ s1070363213040348. Acesso em: 02 abr. 2019.

INHELDER, B.; PIAGET, J. The psychology of the child. New York: Basic Books, 1969.

JUSTI, R.; MENDONÇA, P. Usando analogias com função criativa: uma nova estratégia para o ensino de Química. Educació Química, Barcelona, n. 1, p. 24-29, 2008. Disponível em: https://doi. org/10.2436/20.2003.02.4. Acesso em: 02 abr. 2019.

LYTHCOTT, J. Problem solving and requisite knowledge of chemistry. Journal of Chemical Education, Washington, v. 67, n. 3, p. 248, 1990. Disponível em: https://doi.org/10.1021/ed067p248. Acesso em: 02 abr. 2019.

MORTIMER, E. F. Pressupostos epistemológicos para uma metodologia de ensino de Química: mudança conceitual e perfil epistemológico. Química Nova, São Paulo, v. 15, n. 3, p. 242-249, 1992.

NOVAK, J. D. Concept maps and Vee diagrams: two metacognitive tools to facilitate meaningful learning. Instructional Science, Amsterdã, v. 19, n. 1, p. 29-52, 1990. Disponível em: https://doi. org/10.1007/bf00377984. Acesso em: 02 abr. 2019.

ÖZMEN, H. Some Student Misconceptions in Chemistry: a Literature Review of Chemical Bonding. Journal of Science Education and Technology, Amsterdã, v. 13, n. 2, p. 147-159, 2004. Disponível em: https://doi.org/10.1023/b:jost.0000031255.92943.6d. Acesso em: 02 abr. 2019.

PFUNDT, H.; DUIT, R. Bibliography: students' alternative frameworks and science education. 4. ed. Kiel, Germany: IPN, 1994.

PIAGET, J. The child's conception of the world. New York: Harcourt, 1929.

POSNER, G. J. et al. Accommodation of a scientific conception: towards a theory of conceptual change. Science Education, Hoboken, v. 66, p. 211-227, 1982. Disponível em: https://doi.org/10.1002/ sce.3730660207. Acesso em: 02 abr. 2019.

RODRIGUES, J. M. P.; SILVA, G. P. O Sistema de Organização Modular de Ensino (SOME) na ótica de egressos no município de Breves-Pará. Revista Brasileira de Educação do Campo, Tocantinópolis, v. 3, n. 1, p. 260-286, 2018. Disponível em: https://doi.org/10.20873/uft.2525-4863.2018v3n1p260. Acesso em: 02 abr. 2019. 
SANTOS, W. L. P. Educação CTS e cidadania: confluências e diferenças. Amazônia: Revista de educação em ciências e matemáticas, Belém, v. 9, n. 17, p. 49-62, 2012. Disponível em: https://doi. org/10.18542/amazrecm.v9i17.1647. Acesso em: 02 abr. 2019.

TENÓRIO, I. Bolhas flutuantes no gelo seco. 2012. Disponível em: https://youtu.be/vReRK8nmWKY. Acesso em: 02 abr. 2019.

TENÓRIO, I. Submarino na garrafa. 2011. Disponível em: https://youtu.be/R6XCLdEEj0c. Acesso em: 02 abr. 2019.

THIELE, R. B.; TREAGUST, D. F. Using analogies in secondary chemistry teaching. Perth: SMEC, 1991.

TREAGUST, D. F. Development and use of diagnostic tests to evaluate students' misconceptions in science. International Journal of Science Education, Londres, v. 10, n. 2, p. 159-169, 1988. Disponível em: https://doi.org/10.1080/0950069880100204. Acesso em: 02 abr. 2019.

VIENNOT, L. Le Raisonnement Spontané en Dynamique Elémentaire. Tesis Doctoral. Paris: Université de Paris, 1976.

VYGOTSKY, L. S. Mind in society: the development of higher psychological processes. Cambridge: Harvard University Press, 1978.

WARTHA, E. J; LEMOS, M. M. Abordagens investigativas no ensino de Química: limites e possibilidades. Amazônia: Revista de Educação em Ciências e Matemáticas, Belém, v. 12, n. 24, p. 5-13, 2016. Disponível em: https://doi.org/10.18542/amazrecm.v12i24.3172. Acesso em: 02 abr. 2019.

WHITE, R. T.; GUNSTONE, R. F. Probing understanding. Great Britain: Falmer Press, 1992. 